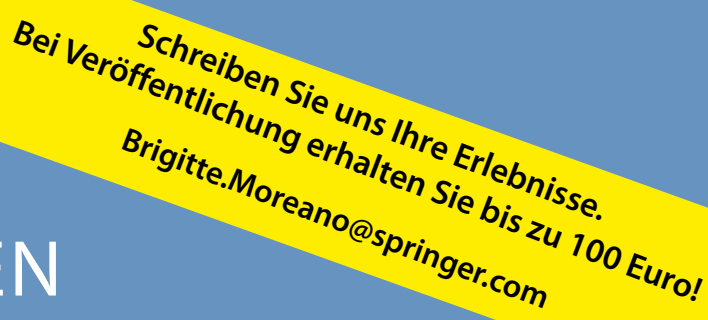

WAS MMW-LESER ERLEBEN

Ärztliche Erfahrung beschränkt sich nicht auf medizinisches Fachwissen. Sie entsteht auch aus den mehr oder minder alltäglichen, heiter, ärgerlich oder nachdenklich stimmenden Erlebnissen mit Patienten, Kollegen und Mitarbeitern. Senden Sie uns Ihre Geschichte an: Brigitte.Moreano@springer.com. Für jeden veröffentlichten Text erhalten Sie bis zu 100 Euro.

\title{
So viel Mühe und kein Dank
}

— Regelmäßig beschleicht mich das Gefühl, dass gerade jene Patienten unserer Praxis den Rücken kehren, um die ich mich besonders bemüht habe. So ließ ein alter Herr, dem ich viel Zeit geopfert hatte, obgleich es ihm recht gut ging, gerade seine Unterlagen zu einer Nachbarpraxis schicken.

Eigentlich litt er nur unter Arthrose und einer Hypertonie, die in meinen Augen gut eingestellt war. Die Arthrose machte ihm keine Probleme, der Hochdruck umso mehr. Er glaubte mir nicht, dass seine Werte für einen Mann, der hart auf die $90 \mathrm{zu}$ steuert, in Ordnung sind. Er klagte über vielfältige Nebenwirkungen, bis wir endlich die Medikamentenauswahl zu seiner Zufriedenheit getroffen hatten. Er nahm un- zählige selbst bezahlte Kapseln und Pülverchen nebenbei, die ich inm eines Tages geduldig auseinandersortierte, um Sinnvolles von Überflüssigem zu trennen. Jeder seiner Termine wurde gnadenlos überzogen.

Er war nicht lange bei mir, vielleicht ein halbes Jahr. Ich hätte es ja wissen müssen! Wer in diesem hohen Alter den Arzt wechselt, bleibt auch unserer Praxis wahrscheinlich nicht treu. Aber er war freundlich, und ich dachte, wir kämen gut miteinander aus. Eigentlich sollte ich sagen: „Weg mit Schaden! Reisende soll man nicht aufhalten, und die nun

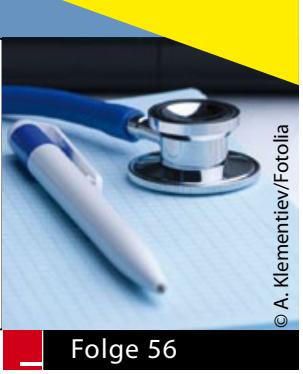

\section{Verkehrte Hierarchie}

- Als Assistenzarzt in einer kleineren Berliner Spezialklinik vor vielen Jahren hatte ich den Zusammenhang der Erkrankung einer Krankenschwester an Typhus abdominalis mit deren beruflicher Tätigkeit auf einer Infek-tionsstation gutachterlich zu klären.

Meine Anfrage an die Klinikleitung ergab, dass sich die Krankenschwester nur zu einem Zeitpunkt infiziert haben konnte, zu dem sie sich wegen einer Lobärpneumonie im Krankenstand befand. Die Anerkennung des Typhus als Berufskrankheit wäre somit zu verneinen gewesen.

Kurz nach Eingang des Antwortschreibens rief mich der Chefarzt der Infektions- klinik an und bat um einen Termin, um mit mir den Fall zu besprechen. Ein Chefarzt bittet einen Ausbildungsassistenten um einen Termin - das widersprach allen hierarchischen Gepflogenheiten -, da musste wohl etwas faul sein.

Es ergab sich Folgendes: Die zu Begutachtende bewohnte im gleichen Haus eine Wohnung und wurde ärztlich und pflegerisch von ihrer Station betreut. Als es ihr besser ging, hatte sie aus Kollegialität und Pflichtgefühl stundenweise auf ihrer Station ausgeholfen, war somit, obwohl noch im Krankenstand befindlich, nachweislich exponiert gewesen und hatte sich in Ausübung ihres Berufes infiziert.
Dass es sich hierbei um einen Verstoß gegen die Krankenordnung handelte, erschien unerheblich. Der Gutachtenauftrag bezog sich ja auf rein arbeitsmedizinische Fragen. Eine Melde- oder Anzeigepflicht bestand nicht. Wir vereinbarten die Weglassung des Schriftwechsels. Die Anerkennung des Typhus abdominalis als Berufskrankheit konnte empfohlen werden.

Obwohl vieles eine Frage der Formulierung ist, sollte man sich bei seinen Entscheidungen möglichst im Rahmen der Gesetzlichkeit bewegen.

DR. MED. ECKART TÖPPICH, ULLERSDORF - 